\author{
G. Abitova \\ PhD, the Candidate of Technical Sciences, Associate Professor of ICT \\ Educational Program \\ gulnara.abitova@astanait.edu.kz, orcid.org/0000-0003-3830-6905 \\ Astana IT University, Kazakhstan \\ V. Nikulin \\ $\mathrm{PhD}$, Associate Professor of the Faculty of Electrical Engineering and \\ Computer Science \\ vnikulin@binghamton.edu,orcid.org/0000-0003-4977-0332 \\ Binghamton University, NY, USA
}

\title{
T. Zadenova
}

Doctoral Student of Systems Analysis and Management Department tan.zadenova21@gmail.com, orcid.org/0000-0002-9146-1034

L.N. Gumilyov Eurasian National University, Kazakhstan

\section{NEURAL NETWORK MODELING AND OPTIMISING OF THE AGGLOMERATION PROCESS OF SULPHIDE POLYMETALLIC ORES}

\begin{abstract}
During the operation of the lead-zinc production while processing of polymetallic ores, problems arose related to the quality of products and the efficient use of equipment - agglomeration furnace and crushing apparatus. Previously, such issues were resolved due to the experiences and based on mathematical modeling of processes. The mathematical model for optimizing unnecessary such operating mode is a difficult program. Performing calculations is required a fairly large investment of time and resources. Therefore, the program of the mathematical model for optimizing the operating mode of the agglomeration furnace and the crushing device for sinter firing was replaced with a neural network by implementing the process of training the network based on the results of calculations on a mathematical model. The results obtained showed that neural network models were more accurate than mathematical models, which made it possible to solve production optimization problems of great complexity. The use of neural networks for modeling technological processes has made it possible to increase the efficiency of product quality control systems and automatic control systems for the roasting of sulfide polymetallic ores.

Keywords: neural network technology, modeling of technological processes, optimizing the mode, agglomeration furnace, control system and industrial automation

\section{Introduction}

In a modern study with the development of equipment and technology in the industry, the range of tasks for the solution of which it becomes necessary is significantly expanding for the use of modern research methods, the search for ways to optimize the operating modes of technological lines, as the creation and effective use of modern systems for automatic and automated control of production processes using modern tools and artificial intelligence systems. Neural networks are one of the directions in the development of artificial intelligence systems, including in decision-making and optimization of modern technological processes in the industry.
\end{abstract}


A promising area of application of the tools of the theory of artificial neural networks is the modeling of complex technological processes in the metallurgical industry of the mining and metallurgical complex. Mathematical models of technological processes are necessary for the application of effective modern methods and tools for studying the influence of technology on the properties of the final product of the appropriate quality, as for the tasks of optimizing management and making high-quality decisions.

Mathematical models are often simplified, limiting their actions to certain assumptions. Although the literature does not provide examples of the use of neural networks for modeling this kind of dependencies (in particular, in the lead-zinc production of non-ferrous metallurgy), the flexibility of neural network models allows them to be used to simulate the technological process and in the metallurgical production of non-ferrous metals during the processing and roasting of sulfide polymetallic ores.

In metallurgical industries, the task of introducing innovative technologies is attractive, which can accelerate research in obtaining new promising metallurgical alloys, improve the quality and safety of methods for obtaining smelted metal, and reduce its cost. Due to the complex nature of the change in material properties, depending on the chemical composition of the ores being processed, the concentration of metals in the ores, heat treatment modes, and test conditions, the ability to choose the exact mathematical relationship between the composition and properties quickly decreases and may become impracticable [1].

A further solution to the problem of optimizing the control of metallurgical processes for the processing of polymetallic sulfide ores is possible by solving the problems of controlling large melting units (roasting and agglomeration furnaces, oxygen converters, etc.) including complex multiparametric processes. The introduction of automated neural network systems for melting process control will improve the quality of the smelted metal, reduce its cost (including the prime cost) and increase the safety of the technological process.

\section{Review of Literature}

A lot of modern works and scientific researches are devoted to the study of neural network technologies and their application in the control of energy-technological installations, as well as to the issues of modeling for energy consumption. The work [2] considers the issues of creating, teaching, and testing an artificial neural network that simulates the thermal operation of a continuous furnace in metallurgical production. Since the $90 \mathrm{~s}$, the neural network approach has been actively implemented in the tasks of predicting the load of electricity and gas consumption [3].

The work [4] considers the factors and initial data used in forecasting the loads on power systems. The problem of constructing a control system for a distributed energy system based on a neural network is studied in next work [4]. The problem of automated control of energy consumption was investigated by the other scientist in [5]. The work [6] are presented a description of a neural network algorithm for ensuring maximum load in electrical networks.

In another study are developed a neural network for operational control and monitoring of uncertain situations during the operation of power plants [7]. The work [8] are presented preliminary results of a study of the capabilities of neural network systems as a means of training and operational assistance to a dispatcher at power plants.

Other scientists proposed a method of using genetic algorithms to find the optimal solution to the problem of placing measuring sensors in power plants [9]. The next work has proposed a method for using artificial neural networks to detect internal malfunctions of induction machines, providing real-time operation [10]. The issues of modeling heat power plants and neural network modeling are also devoted to the work [11]. 
Thus, today there are no universal methods for their application in lead-zinc production, in particular, for modeling processes for processing and agglomeration roasting of polymetallic ores. The review confirms the relevance of our research and its relevance for the development of new innovative technologies and Industry 4.0.

\section{Proposed Approach and the New Value of Research}

The recent development of neural network technology can create a universal methodology for assessing the accuracy of mathematical models in the problems of controlling heattechnological installations, as well as in modeling the thermal operation of roasting furnaces in lead-zinc production.

This paper proposes the use of neural network technology for calculating and modeling a furnace-crushing heat-technological installation to increase their efficiency and reduce cost. Modeling based on neural networks provides a new approach to the design of control systems for complex processes in lead-zinc production, which ensures the innovativeness of the study.

The novelty of the research lies in the fact that: a new technique has been developed for using neural networks to simulate the modes of continuous technological processes of loading and unloading concentrates into roasting furnaces and processing of sulfide polymetallic ores; a neural network model of furnace-crushing was created to solve the problem of calculating a roasting furnace, crushing, as well as new technology to optimize the operating mode unit to increase their efficiency in lead-zinc production.

\section{Materials and Research Methods}

The research technique involves the use of neural networks to determine the accuracy of the results obtained when solving heat transfer problems using multipurpose computing systems. It is necessary to use mathematical models that reflect the operation of a heating plant and associated equipment to make a reasonable choice of a heating plant. The mathematical models used for these purposes in the form of computer programs have a complex structure, large volumes, and take a significant amount of time for calculations.

The task of the modeling is to optimize the operating modes of the furnace-crushing sinter plant and to determine, for the optimal mode, technically substantiated rates of fuel consumption for the furnace, electric energy for the crusher.

To determine the connections between the operating modes of the furnace and the crusher, the task also includes determining the regularities of the influence of changes in the generalized size of the pallet load and the parameters of the heating quality on the time of agglomerating firing and determining the factors affecting the consumption of crushing energy.

It is also necessary to substantiate technological limitations, to investigate the change in the objective function from the varied parameters. The method of enumerating options based on dependencies was used as a method for optimizing the cost of a manufactory redistribution.

Description of the mathematical model of the furnace

The model is designed for an agglomeration furnace operating in a stationary mode. The stationary heat flux in the loaded furnace charge can be considered equal to the amount of heat transferred from the gases to the loaded charge by convection. Under these assumptions, the loaded charge from the point of view of radiation heat transfer can be considered as an ideal lining. Let us assume that the gas volume in the working space of the furnace is isothermal. Since the process of loading and unloading the metal charge is continuous, the temperature over the entire heated surface of the metal charge is currently constant [12].

The mathematical model is based on the solution of the conjugate problem of heat transfer in the gas-charge-agglomerate system. The method of discrete satisfaction of boundary 
conditions was adopted as a mathematical method of modeling [11-12]. The algorithm for solving the problem includes 9 stages and is presented below, in figure 1 .

The calculation determines the specific consumption of air supplied for combustion, the lowest heat of combustion of the fuel, the specific output, and the percentage of combustion products. To calculate the combustion process, a set of programs is used [13-14]. The parameter that needs to be optimized when selecting the operating mode of the furnace-sinter crushing plant is the minimum cost of the workshop redistribution.

Description of the model, optimization of the operating mode of the furnace-agglomeration crushing plant

A universal economic parameter (workshop cost) is most suitable as an objective function to optimize the operating mode of the agglomeration furnace. The workshop cost consists of two types of costs: direct and indirect. Direct costs are divided into basic materials and semifinished products, basic and additional wages. Indirect costs are divided into conditionally variable (proportional) and conditionally fixed [13-14].

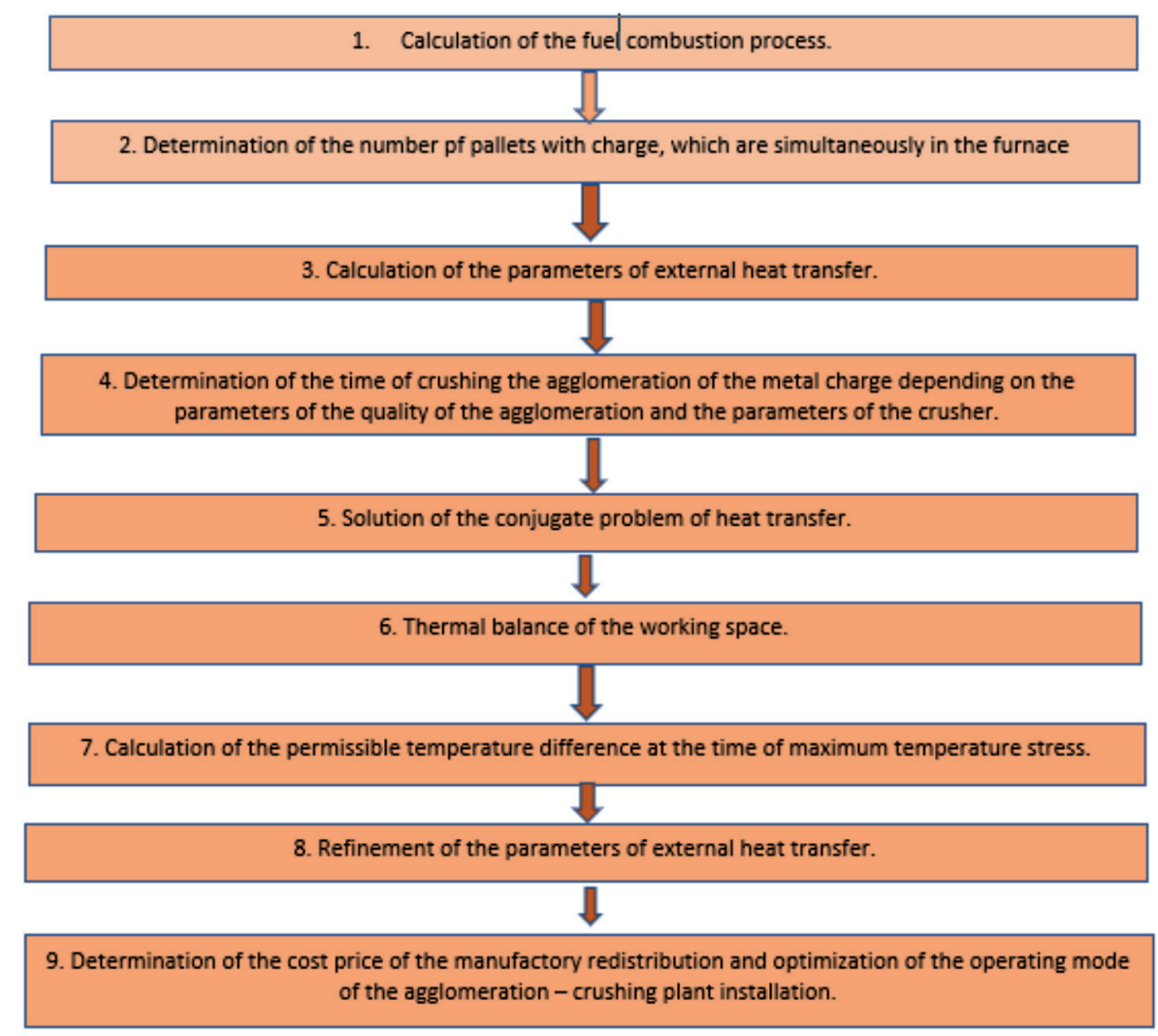

Fig. 1. Algorithm for solving the problem for modeling an agglomeration furnace

\footnotetext{
Choosing the Limitations of the Mathematical Model and Setting up a Computational Experiment

It is difficult to use the above algorithm to determine the optimal operating parameters based on an enumeration of options, the amount of computation is large. Therefore, an algorithm is used, the essence of which is to set up a computational experiment. It is necessary to know how the objective function will change from changing operating parameters [15].

To determine such a dependence, it is necessary to reasonably set the intervals of variation of the varied parameters. The boundaries of the various intervals are determined based on the following conditions:
} 
1) For the final heating temperature of the metal on the surface, the range of variation is in the range from the temperature at which firing cannot be performed (the metal loses its plasticity) to the melting point of the metal (the metal turns into a liquid state).

2) For the permissible temperature difference at the end of metal heating, the range of variation is from a temperature drop close to zero $\left(5-10^{\circ} \mathrm{C}\right)$ to the temperature difference between the melting point of the metal and the temperature of the beginning of firing. In practice, it is advisable to reduce this range somewhat by setting it in the range from 15 to $150^{\circ} \mathrm{C}$.

Here, an algorithm is used, which is to set up a computational experiment. It is necessary to know how the objective function will change from changing operating parameters $[13,14$, and 15].

To determine such a dependence, it is necessary to reasonably set the intervals of variation of the varied parameters. The required dependence $y=f\left(x_{1}, x_{2}, x_{3}\right)$ is in the form (Eq.1):

$$
y=b_{1}+b_{2} x_{1}+b_{3} x_{2}+b_{4} x_{3}+b_{5} x_{1} x_{2}+b_{6} x_{1} x_{3}+b_{7} x_{2} x_{3}+b_{8} x_{1}^{2}+b_{9} x_{2}^{2}+b_{10} x_{3}^{2}
$$

Where $y$ is an optimization parameter; $x_{1}, x_{2}, x_{3}$ - variable parameters.

The optimization problem is solved taking into account 8 constraints (Table 1).

Table 1. The 8 constraints for optimization

\begin{tabular}{|c|c|}
\hline Number of Constrain & Type of Constrain \\
\hline The first constrain & $\begin{array}{l}\text { is the temperature of the gases in the working space of the sintering furnace, which } \\
\text { cannot exceed the actual combustion temperature of the fuel; }\end{array}$ \\
\hline The second constrain & $\begin{array}{l}\text { use the rate of delivery of pallet blanks from the kiln, which should not be less than } \\
\text { the firing time.; }\end{array}$ \\
\hline The third constrain & $\begin{array}{l}\text { is the allowable temperature difference during the initial sintering period, } \\
\text { determined by the allowable temperature stresses; }\end{array}$ \\
\hline The fourth constrain & \multirow{3}{*}{$\begin{array}{l}\text { are the maximum temperatures for use of refractory and insulating materials from } \\
\text { which the three-layer masonry of the furnace is made; }\end{array}$} \\
\hline The fifth constrain & \\
\hline The sixth constrain & \\
\hline The seventh constrain & is the maximum possible gas flow rate for the furnace; \\
\hline The eighth constrain & is the productivity of the agglomeration furnace. \\
\hline
\end{tabular}

The Structure of the Mathematical Model of the Furnace-Crushing Agglomeration Plant

The proposed unit model is designed to optimize the operating mode of the agglomerationcrushing furnace system, calculate the rates of energy consumption for the unit at a minimum cost of the workshop redistribution. Figure 2 shows the interaction of the components of the furnace-agglomeration crushing plant model. 


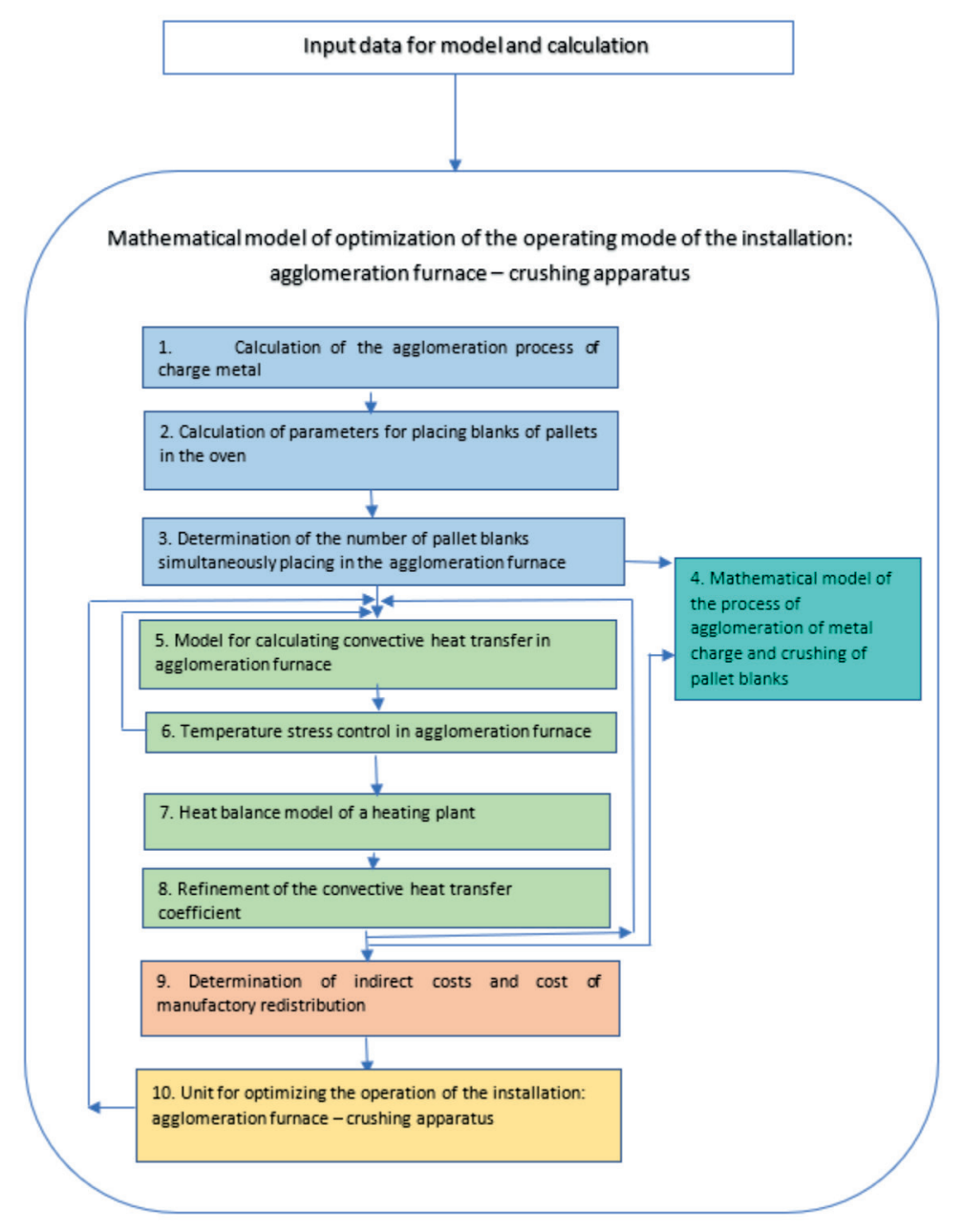

Fig. 2. Block diagram of the model: agglomeration furnace - crusher

\section{Results and Discussion}

We replaced the program of the mathematical model for optimizing the operating mode of the industrial plant: agglomeration furnace and crushing device with a neural network by implementing the process of the so-called network learning based on the results of calculations on a mathematical model.

The neural network has generalized the information received in the form of functional connections within itself and in some cases has replaced the mathematical model of the furnace-sinter crushing plant for decision-making.

The learning set is a database in the form of a Microsoft Excel spreadsheet. Each row in the table is one observation that includes the various values of seven variable input variables and an output quantity.

1. The training of the neural network to determine the number of pallet blanks in the agglomeration furnace was carried out in accordance with the algorithm shown in figure 3 below. 


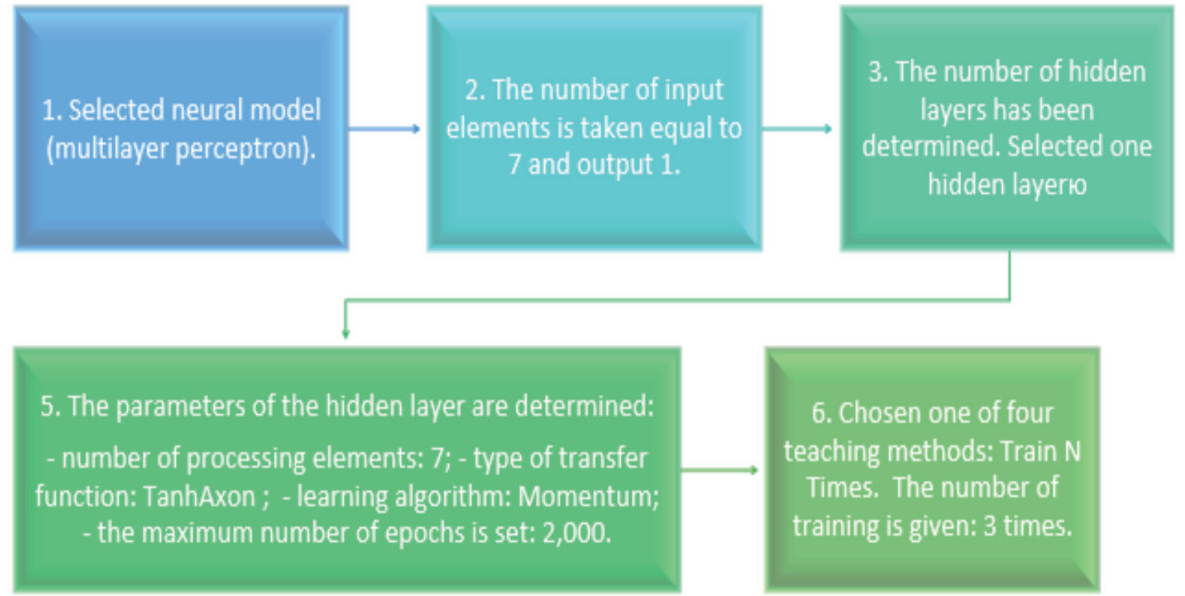

Fig. 3. The algorithm of the training of the neural network

2. After training on the data obtained from the calculation in the program for optimizing the operating mode of the furnace-crushing sinter plant, the neural network is ready for operation and was used to make forecasts and make instant decisions.

As a result, the best learning outcomes of neural networks were the learning outcomes presented in tables 2-3. Table 2 presents a comparative analysis of the learning outcomes and calculation according to the program to determine the number of pallet blanks in the agglomeration furnace.

Table 3. Comparative analysis of the learning outcomes and calculation of pallet blanks in the agglomeration furnace

\begin{tabular}{|l|c|}
\hline \multicolumn{1}{|c|}{ Calculation and learning outcomes } & Number of pallet blanks in a furnace \\
\hline $\begin{array}{l}\text { The total number of pallets obtained from the calculation in the } \\
\text { program for optimizing the operating mode of the installation: } \\
\text { agglomeration furnace crushing apparatus }\end{array}$ & -1955 \\
\hline $\begin{array}{l}\text { The total number of pallets obtained as a result of training the neural } \\
\text { network }\end{array}$ & -1943 \\
\hline
\end{tabular}

For this training, it was obtained that the final root-mean-square error was: MSE $=0.0128$.

Comparison of the number of pallet blanks in the agglomeration furnace, obtained as a result of calculating the mathematical model, with the number of pallet blanks obtained after training the neural network, is also shown in figure 4.
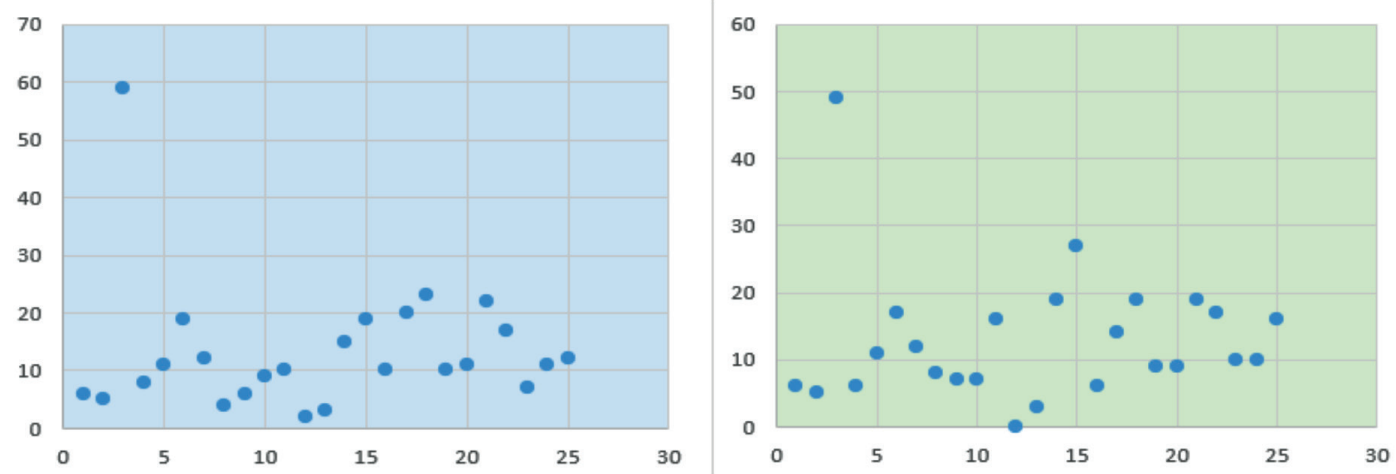

Fig. 4. Comparison of the number of pallet blanks in the furnace, obtained as a result of the calculation and the number of pallet blanks obtained after training the neural network 
Table 4 presents a comparative analysis of the results of training and calculation according to the program for determining the agglomeration time of the metal charge and pallet blanks. Table 5 presents a comparative analysis of the results of training and calculation according to the program for determining the surface temperature of the metal charge at the end of agglomeration.

Table 4. Comparative analysis of the results of training and calculation according to the program for determining the agglomeration time of the pallet blanks

\begin{tabular}{|l|c|}
\hline \multicolumn{1}{|c|}{ Calculation and learning outcomes } & Agglomeration time of pallet blanks \\
\hline $\begin{array}{l}\text { The sum of the agglomeration time numbers of pallet blanks for all } \\
\text { experiments, obtained by calculation in the program for optimizing } \\
\text { the operating mode of the sintering furnace-crusher }\end{array}$ & -232844 \\
\hline The sum of numbers obtained after training the neural network & -232347 \\
\hline
\end{tabular}

With such training, the final root-mean-square error was: MSE $=0.0109$ to determine the time of agglomeration of the metal charge and pallet blanks.

Table 5. Comparative analysis of the results of training and calculation according to the program for determining the surface temperature of the agglomeration

\begin{tabular}{|l|c|}
\hline \multicolumn{1}{|c|}{ Calculation and learning outcomes } & $\begin{array}{c}\text { Number by surface temperature of pallet } \\
\text { blanks at the end of agglomeration }\end{array}$ \\
\hline $\begin{array}{l}\text { The total number of the temperature of the metal surface at the } \\
\text { end of sintering, obtained from the calculation in the program for } \\
\text { optimizing the operating mode of the sintering furnace-crusher }\end{array}$ & -109115 \\
\hline $\begin{array}{l}\text { The total number of the surface temperature of the pallet blanks at } \\
\text { the end of the agglomeration, obtained as a result of training the } \\
\text { neural network }\end{array}$ & -109090 \\
\hline
\end{tabular}

With this training, the final root-mean-square error was MSE $=0.011311147$ to determine the surface temperature of the metal charge at the end of the agglomeration.

Some of the learning outcomes of the neural network according to the proposed algorithm are presented in figure 5 .
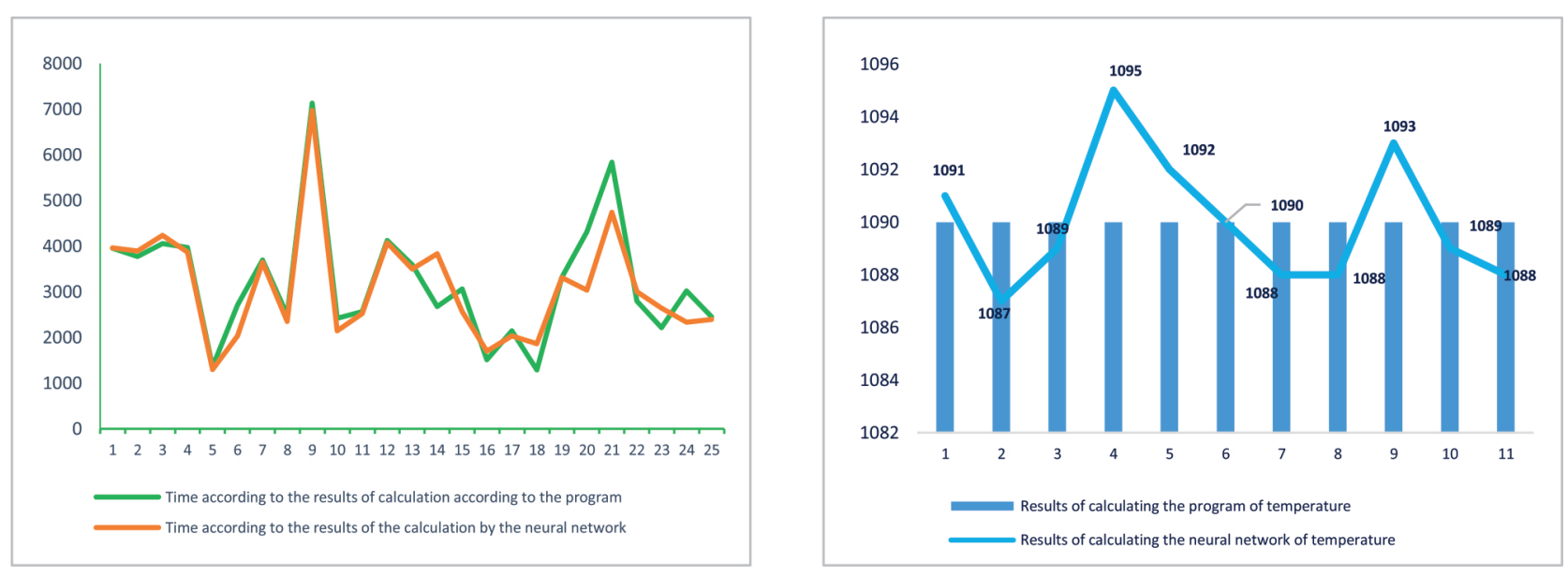

Fig. 5. The learning outcomes of the neural network according to the proposed algorithm

Thus, according to the results of the experiments, as a result of using the trained neural network, the following deviations were obtained between the results calculated in the 
installation optimization program: agglomeration furnace-crusher and the neural network (Table 6).

Table 6. Comparing results calculated in the installation optimization program: agglomeration furnace-crusher and the neural network

\begin{tabular}{|l|c|c|c|}
\hline \multicolumn{1}{|c|}{ Deviation } & $\begin{array}{c}\text { Deviations in the number } \\
\text { of pallet blanks in the } \\
\text { agglomeration furnace, } \mathbf{p c s} .\end{array}$ & $\begin{array}{c}\text { Deviation in time of } \\
\text { agglomeration of pallet } \\
\text { blanks, sec. }\end{array}$ & $\begin{array}{c}\text { Deviations in sinter surface } \\
\text { temperature at the end of } \\
\text { agglomeration, }{ }^{\circ} \mathbf{C}\end{array}$ \\
\hline maximum deviation & 16 & 682 & 37 \\
\hline mean deviation & 12 & 497 & 25 \\
\hline minimum deviation & 1 & 8 & 1 \\
\hline
\end{tabular}

For clarity, figure 6 shows the dependences of the workshop cost on the surface temperature of the pallet blanks at the end of sintering, obtained on the model of the installation: agglomeration furnace-crusher for two different versions.

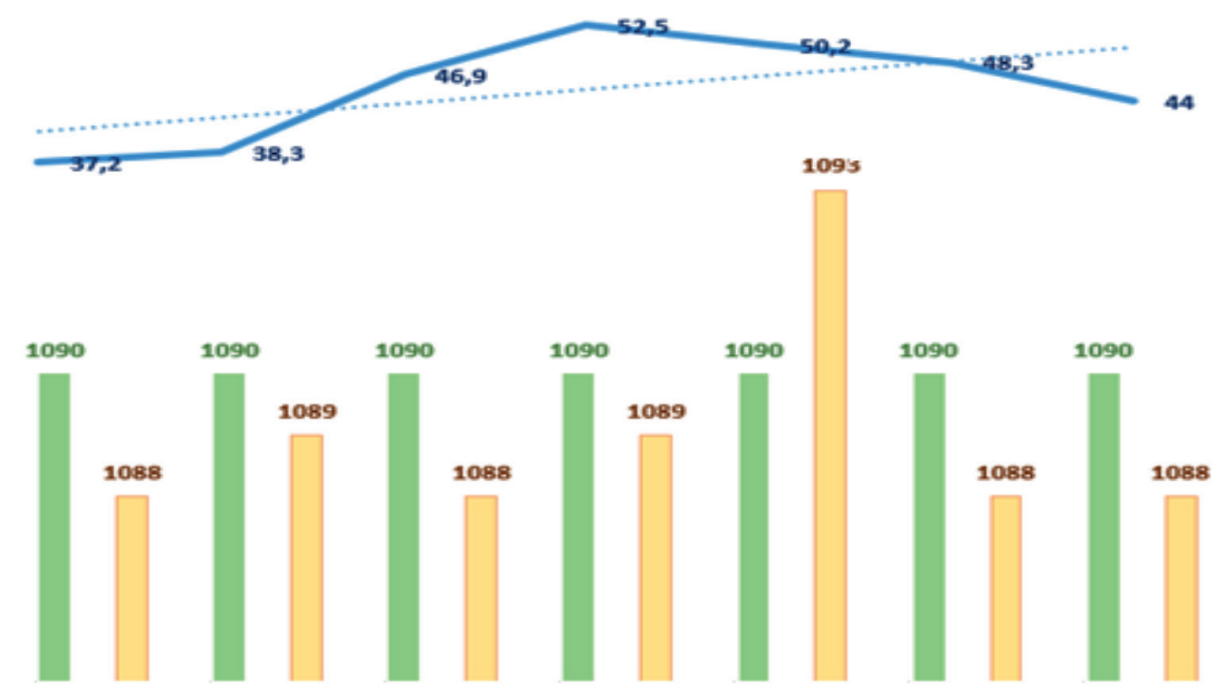

Fig. 6. Dependences of the workshop cost on the surface temperature

For clarity, figure 6 shows the dependences of the workshop cost on the surface temperature of the pallet blanks at the end of sintering, obtained on the model of the installation: agglomeration furnace-crusher for two different versions.

Based on the obtained results of training the neural network, the following results were obtained:

- the network error in terms of the number of pallet blanks in the agglomeration furnace ranged from $11 \%$ to $43 \%$;

- the network error in terms of the time of agglomeration of pallet blanks ranged from $0.2 \%$ to $29 \%$;

- the network error in terms of the surface temperature of the pallet blanks was from $0.09 \%$ to $3 \%$.

According to the obtained tabular data in tables 3-5 and the plotted graphs shown in figures $5-6$, it can be concluded that in the proposed model of the agglomeration kiln, the temperature distribution of the kiln, pallet blanks, and a metal charge is close to the experimental data. The range of relative error in temperature is $0-4.16 \%$. 
Thus, the obtained neural model adequately describes the real processes during the agglomeration of the charge and the firing of pallet blanks in the furnace. It can be used to make forecasts and make instant decisions in the design of heating equipment and control.

\section{Conclusion}

During the operation of heating and power plants in metallurgical production, in particular, lead-zinc production in the processing of polymetallic ores, problems arise associated with the quality of products and the effective use of agglomeration furnace and crushing apparatus. Recently, mathematical modelling of the processes occurring in heat-technological installations has begun to be actively used for these purposes. However, the mathematical model for optimizing the operating mode of the installation is a complex program, which includes several dozen calculation modules.

Therefore, we replaced the program of the mathematical model for optimizing the operating mode of the agglomeration kiln and the crushing device for firing with a neural network. The use of neural networks to simulate technological processes in lead-zinc production ensured an increase in the efficiency of product quality control systems and automatic control systems for roasting of polymetallic ores, optimize production costs (by $3 \%$ ), and also increase the efficiency of energy production.

In addition, neural network models turned out to be more accurate and more adequate than mathematical ones, and make it possible to solve production optimization problems of any complexity in lead-zinc production. Thus, neural network modelling of technological processes for processing and agglomeration roasting of polymetallic ores provides an innovative approach to the design of control systems and their modelling for optimization problems and increasing production efficiency.

\section{References}

1. Abitova, G., Abdrakhmanova, E., Bekish, Z., Zadenova, T., Rzayeva, L., \& Kulniyazova, K. (2021, April). Study and Simulation of Control System of the Process of Roasting in Fluidized Bed Furnaces of Polymetallic Sulfide Ores under Uncertainty. In 2021 IEEE International Conference on Smart Information Systems and Technologies (SIST) (pp. 1-6). IEEE.

2. Vekhnik, V.A. (2002). Thermal Neural Network Modeling Continuous Furnace Operation Metallurgical Heat Engineering. The Proceedings of the National Metallurgical Academy of Ukraine, 8, Publisher: NMetAU, Dnepropetrovsk, 226.

3. Andreeva, A.Yu., Romanchuk, V.A. (2015). The use of neurocomputer technologies in methods of managing complex objects. Modern technology and technology, 4 [Electronic resource]. URL: https:// technology.snauka.ru/2015/04/6557 (date of access: 15.04.2021).

4. Srinivasan, D., Chang, C.S., \& Liew, A.C. (1995). Demand forecasting using fuzzy neural computation, with special emphasis on weekend and public holiday forecasting. IEEE Transactions on Power Systems, 10(4), 1897-1903.

5. Santoso, N.I., \& Tan, O.T. (1990). Neural-net based real-time control of capacitors installed on distribution systems. IEEE Transactions on Power Delivery, 5(1), 266-272.

6. Caudana, B., Conti, F., Helcke, G., \& Pagani, R. (1995). A prototype expert system for large scale energy auditing in buildings. Pattern recognition, 28(10), 1467-1475.

7. Hiyama, T., Kouzuma, S., Imakubo, T., \& Ortmeyer, T.H. (1995). Evaluation of neural network based real time maximum power tracking controller for PV system. IEEE transactions on Energy Conversion, 10(3), 543-548.

8. Thomas, R.J., Sakk, E., Hashemi, K., Ku, B.Y., \& Chiang, H. (1990, May). On-line security classification using an artificial neural network. In IEEE International Symposium on Circuits and Systems (pp. 2921-2924). IEEE. 
9. Aggoune, M.E., \& Vadari, S.V. (1990, November). Use of artificial neural networks in a dispatcher training simulator for power system dynamic security assessment. In 1990 IEEE International Conference on Systems, Man, and Cybernetics Conference Proceedings (pp. 233-238). IEEE.

10. Michalik-Mielczarska, G. (1992). Dynamilc state estimation of a synchronous generator using neural-networks techniques, (92/15), 21-28.

11. Gorbunov, V.A. (2011). Using neural network technologies to improve energy efficiency heat technology installations. in Monograph, "Ivanovsky State Power Engineering University named after IN AND. Lenin", Ivanovo, 476.

12. Tomashpolsky V.I. and other. (1992). Heat exchange and thermal modes in industrial furnaces, Minsk: Higher school, 217.

13. Sokolov, A.K. (2002). Optimization of operating and design parameters and improvement of calculation methods for gas heating furnaces", in Diss.work, 340.

14. Yu, D., Utigard, T.A., \& Barati, M. (2014). Fluidized bed selective oxidation-sulfation roasting of nickel sulfide concentrate: Part II. Sulfation roasting. Metallurgical and Materials Transactions B, 45(2), 662674.

15. Abitova, G. (2020). Mathematical simulation and study of control stability of the chemicalengineering processes in industry. Scientific Journal of Astana IT University, (4), 4-13. 